\title{
A case study in the Chernobyl zone Part I: Predicting radionuclide transfer to wildlife
}

\author{
N.A. Beresford ${ }^{1}$, S.M. Wright ${ }^{1}$, C.L. Barnett ${ }^{1}$, M.D. Wood ${ }^{2}$, S. Gaschak ${ }^{3}$, \\ A. Arkhipov ${ }^{3}$, T.G. Sazykina ${ }^{4}$ and R. Avila ${ }^{5}$ \\ ${ }^{1}$ Centre for Ecology \& Hydrology, Lancaster Environment Centre, Library Avenue, Bailrigg, \\ Lancaster LA1 4AP, UK, e-mail: nab@ceh.ac.uk \\ ${ }^{2}$ Jones Building, School of Biological Sciences, University of Liverpool L69 3GS, UK \\ ${ }^{3}$ International Radioecology Laboratory, ICC, Post Box 151, Slavutych, \\ 07100 Kiev District, Ukraine \\ ${ }^{4}$ SPA "TYPHOON", 82 Lenin Av., Obnisk, Kaluga Region 249038, Russia \\ ${ }^{5}$ Facilia $A B, 16751$ Bromma, Sweden
}

\begin{abstract}
A number of frameworks have been proposed to assess the protection of wildlife from ionising radiations. In this paper we compare the predictions of transfer parameters recommended by one of these frameworks (FASSET) with observed whole-body ${ }^{90} \mathrm{Sr}$ and ${ }^{137} \mathrm{Cs}$ activity concentrations in a range of mammal and invertebrate species sampled within the Chernobyl exclusion zone. Predicted activity concentrations are generally within the observed ranges and mean predictions for reference organisms are similar to, or circa one order of magnitude higher than, the observed means. However, some predictions are more than one order of magnitude lower than observed values. No data were available for animals to test predictions for the other radionuclides released by the Chernobyl accident. In a separate paper the outputs of this assessment will be used to estimate doses to reference organisms and compare these to observed radiation induced effects reported within the Chernobyl zone.
\end{abstract}

\section{INTRODUCTION}

In recent years, national and international programmes have proposed frameworks and methodologies to assess the protection of wildlife from ionising radiations [e.g. 1,2,3,4]. Whilst some of these are now being used by national authorities [5], there has to date been little attempt to rigorously test their predictions against available data. In part this is because of the lack of sites where radiation induced effects can be observed. One suitable site is the Chernobyl exclusion zone for which considerable amounts of data are available for a wide range of biota across a gradient of exposure rates.

In this paper we apply the methodology presented by Brown et al. [6], which forms part of the FASSET environmental impact assessment framework [4], to estimate the whole-body radionuclide concentrations of wild animals within the Chernobyl exclusion zone and compare these to available data. A separate paper takes this work further to estimate doses and the likely subsequent effects [7].

\section{THE FASSET FRAMEWORK}

The FASSET framework presents look-up tables of concentration ratios (CR) for radionuclides of 19 elements to enable the prediction of the activity concentrations in biota from soil activity concentrations (nominally $0-10 \mathrm{~cm}$ soil layer) [6]. Values of CR were estimated from empirical data or, where these were lacking, by model estimation. Biota are represented by a range of reference 
organisms in seven ecosystem types. Whilst the CR tables are incomplete (i.e. values are not provided for every reference organism - radionuclide combination) advice on addressing data gaps is presented $[4,8]$. The most appropriate terrestrial ecosystems considered in the FASSET framework for the Chernobyl exclusion zone are semi-natural pastures/heathlands and forests. The reference organisms for these ecosystems are: soil micro-organism, soil invertebrate, burrowing mammal, carnivorous mammal, herbivorous mammal, detritivorous invertebrate, bird egg, grass/herb, shrub and tree. Whilst CR values for plant reference organisms are presented, these are not subsequently used within the FASSET methodology to estimate internal radiation exposure of plants [6]. Consequently, we will only consider transfer to animal reference organisms in this paper. The look-up tables provided for semi-natural ecosystems are considerably more comprehensive than those presented for forests. Given that in the collation of empirical CR values for semi-natural reference organisms no differentiation was made on the basis of habitat because of the paucity of data [6], many of the semi-natural ecosystem CR values may also be applicable to the same reference organism in forest ecosystems. Here we will concentrate on application of the semi-natural ecosystem CR values (Table 1), although limited comment is given to comparative results if forest ecosystem values were used.

Table 1. Fresh weight (fw) concentration ratio values recommended in the FASSET framework for selected semi-natural ecosystem reference organisms.

\begin{tabular}{lcc}
\hline Reference organism & ${ }^{90} \mathrm{Sr}$ & Radiocaesium \\
\hline Detritivorous invertebrate & none given & 0.085 \\
Herbivorous mammal & 1.96 & 1.84 \\
Carnivorous mammal & 1.3 & 4.96 \\
Burrowing mammal & none given & 5.0 \\
\hline
\end{tabular}

\section{DATA COMPILATION}

Data on the activity concentrations of radionuclides in animals within the Chernobyl exclusion zone were compiled from four sources:

i) The compilation of Russian language publications summarising studies conducted between 1986 and 1998 on the effects of ionising radiation on wildlife described by Sazykina et al. [9]. Caesium-137 activity concentrations are presented for a range of rodent species.

ii) The database described by Gaschak et al. [10] which contains circa 700 measurements of radionuclide activity concentrations in wild animals made throughout the Chernobyl exclusion zone between 1988 and 2000; these include 8 species of predominantly large mammals.

iii) A review of English language publications; useful data arising from this were restricted to ${ }^{90} \mathrm{Sr}$ and radiocaesium activity concentrations in rodents reported by US workers from studies largely conducted 1994 -96 [11,12].

iv) Studies conducted by the University of Liverpool between 2001 and 2003 which measured ${ }^{90} \mathrm{Sr}$ and ${ }^{137} \mathrm{Cs}$ activity concentrations in a range of invertebrate species and rodents [13].

\section{ESTIMATION OF WHOLE-BODY RADIONUCLIDE ACTIVITY CONCENTRATIONS}

\subsection{Prediction of soil radionuclide activity concentrations}

A number of the available data did not have corresponding radionuclide activity concentrations in soil which could be used to test the FASSET CR values. Furthermore, there were no data reporting activity concentrations of any radionuclides other than ${ }^{134} \mathrm{Cs},{ }^{137} \mathrm{Cs}$ and ${ }^{90} \mathrm{Sr}$ in animals. As a large number of radionuclides were released by the Chernobyl accident and ultimately we want to estimate total doses to animals in the Chernobyl zone [7], a method of estimating radionuclide activity concentrations in soil was required. As most available data were reported with a location and an interpolated surface of ${ }^{137} \mathrm{Cs}$ deposition was available to us (data from measurements made in 1991-2 belonging to the 
Ukrainian co-authors, block kriged to a resolution of $58 \mathrm{~m}$ x $58 \mathrm{~m}$ pixels), predicting soil activity concentrations using a geographical information system (GIS) was the most effective option. Soil activity concentrations of ${ }^{89} \mathrm{Sr},{ }^{90} \mathrm{Sr},{ }^{91} \mathrm{Sr},{ }^{95} \mathrm{Zr},{ }^{95} \mathrm{Nb},{ }^{99} \mathrm{Mo},{ }^{103} \mathrm{Ru},{ }^{106} \mathrm{Ru},{ }^{129} \mathrm{Te},{ }^{132} \mathrm{Te},{ }^{131} \mathrm{I},{ }^{133} \mathrm{I},{ }^{134} \mathrm{Cs}$, ${ }^{136} \mathrm{Cs},{ }^{140} \mathrm{Ba},{ }^{141} \mathrm{Ce},{ }^{144} \mathrm{Ce},{ }^{154} \mathrm{Eu}$ and ${ }^{239} \mathrm{Pu}$ were estimated using distance varying relationships of these radionuclides to ${ }^{137} \mathrm{Cs}$ deposition [14]; activity concentrations of ${ }^{238} \mathrm{Pu}$, ${ }^{241} \mathrm{Am}$ and ${ }^{241} \mathrm{Pu}$ were estimated from their total depositions within the exclusion zone relative to that of ${ }^{137} \mathrm{Cs}$ [15]. No correction of soil ${ }^{241} \mathrm{Am}$ activity concentrations was made to account for in-growth from ${ }^{241} \mathrm{Pu}$ decay as this was assessed as being insignificant over the time period considered.

Activity concentrations in soil were predicted for an area around the sampling location with a radius typical of the home range for the species in question; mean, minimum and maximum soil activity concentrations for the pixels falling within this area were recorded. Where reported sampling locations were not given as latitude-longitude co-ordinates but as, for example, a village name the soil activity concentration in an area of $1 \mathrm{~km}$ radius of the village was estimated. For a limited number of collated sampling sites, soil activity concentrations were reported for ${ }^{90} \mathrm{Sr}$, radiocaesium, ${ }^{154} \mathrm{Eu},{ }^{238} \mathrm{Pu}$, ${ }^{239} \mathrm{Pu}$ and ${ }^{241} \mathrm{Am}$. Predictions are generally within an order of magnitude of observed data (and in the range of available measurements). Figure 1 compares predicted and observed radiocaesium and ${ }^{241} \mathrm{Am}$ soil activity concentrations for some of these sites.

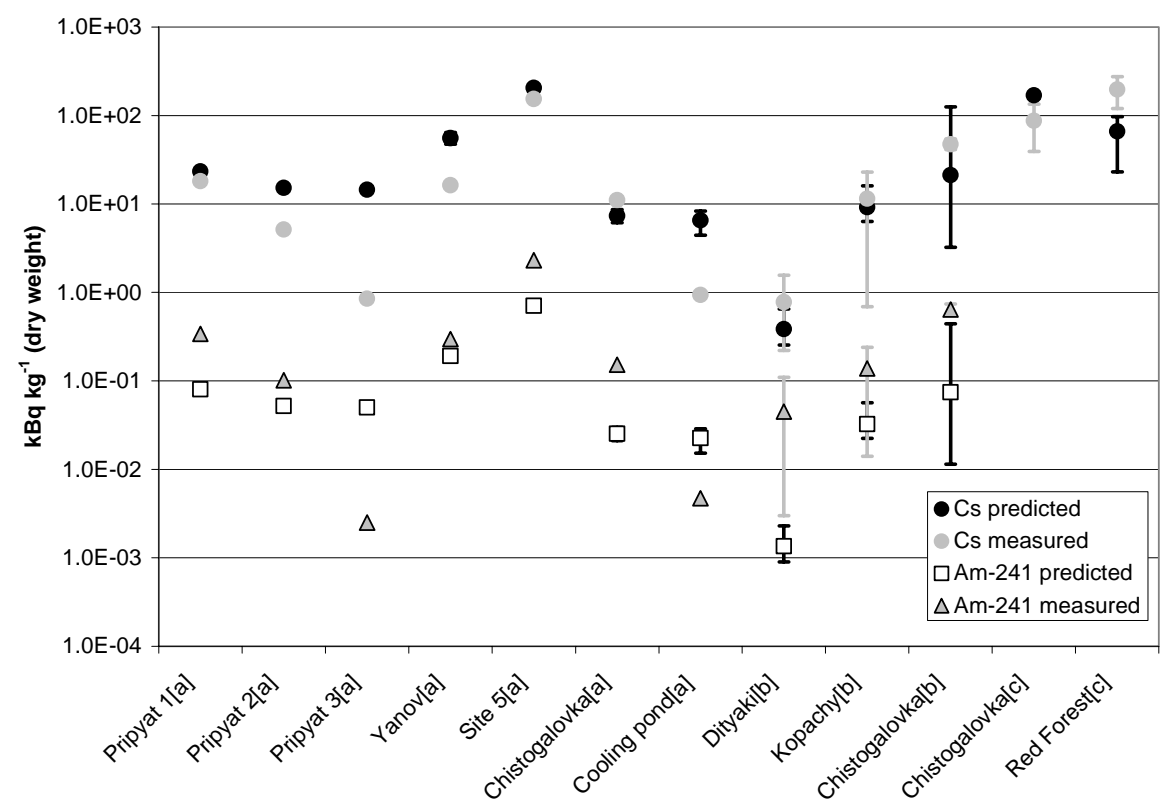

Figure 1. Comparison of measured radiocaesium and ${ }^{241} \mathrm{Am}$ activity concentrations in soils with GIS predictions: (a) [13], ${ }^{137} \mathrm{Cs}$ reported; [b] [11,12], ${ }^{134+137} \mathrm{Cs}$ reported; [c] CEH/IRL data, ${ }^{137} \mathrm{Cs}$ reported. Error bars represent minimum and maximum with the exception of measurements from Refs [11,12] which are \pm SD.

\subsection{Comparison of predicted and observed radionuclide activity concentrations in animals}

Whole-body activity concentrations were estimated as the product of the observed, or GIS predicted, dry weight soil activity concentration and appropriate CR value. The CR value used was selected on the basis of the characteristics of the animal in question with the most conservative value being used if more than one was appropriate (e.g. the radiocaesium CR for burrowing mammals was used if considering a burrowing herbivorous rodent). In the FASSET look-up tables no CR values for 
terrestrial invertebrate species are given for ${ }^{90} \mathrm{Sr}$, therefore, following the advice given in the framework [4], the highest available ${ }^{90} \mathrm{Sr}$ value was used (that recommended for herbivorous mammals). This would be expected to produce conservative estimates [16].

Comparisons of predictions with the observed ${ }^{90} \mathrm{Sr}$ and radiocaesium activity concentrations reported in a range of rodent species (Apodemus spp., Sorex spp., Microtus spp. Clethrionomys galreolus, Muscardinus avellanarius) by Gilhen et al. [13] and Chesser et al. [11] are presented in Tables 2 and 3 respectively. Whilst between species differences have been reported for rodents at sites in the Chernobyl zone [11] predicted values vary little between species as CR values are similar. Tables 2 and 3 present minimum and maximum observed activity concentrations at sampling sites; variation in predicted values is the consequence of the different CR values used dependent upon the species sampled. The mean ratios of predicted to observed activity concentrations for the Gilhen et al. [13] data were 5.7 (range $0.05-28)$ for ${ }^{90} \mathrm{Sr}$ and $25(0.02-294)$ for ${ }^{137} \mathrm{Cs}$; for the data of Chesser et al. [11] the mean ratios were $8.4(0.5-39)$ and $11(0.1-62)$ respectively. For the Chistogalovka sampling sites, radiocaesium predictions were especially high compared to observed data.

Data summarised for rodent species by Sazykina et al. [9] quotes only single values of radiocaesium activity concentration in soil and animals at a range of sites; species sampled were similar to those for the other datasets above with the addition of Mus spp.. Predictions were on average 14-37 times higher than observed data depending upon the CR value used.

Table 2. A comparison of observed (2001-3) and predicted whole-body ${ }^{90} \mathrm{Sr}$ and ${ }^{137} \mathrm{Cs}$ activity concentrations in rodent and invertebrate species sampled at various locations in the Chernobyl exclusion zone [13].

\begin{tabular}{lrrrrrr}
\hline \multirow{2}{*}{ Site name } & \multicolumn{3}{c}{ Small mammals } & \multicolumn{3}{c}{ Detritivorous Invertebrates } \\
& \multicolumn{2}{c}{${ }^{90} \mathrm{Sr}\left(\mathrm{kBqkg}^{-1} \mathrm{fw}\right)$} & \multicolumn{2}{c}{${ }^{137} \mathrm{Cs}\left(\mathrm{kBq} \mathrm{kg}^{-1} \mathrm{fw}\right)$} & \multicolumn{2}{c}{${ }^{137} \mathrm{Cs}\left(\mathrm{kBq} \mathrm{kg}^{-1} \mathrm{fw}\right)$} \\
& Observed & Predicted & Observed & Predicted & Observed & Predicted \\
\hline Pripyat 1 & $1.3-2.1$ & 16 & $0.31-0.79$ & 91 & 0.19 & 1.5 \\
Pripyat 3 & 0.90 & 9.6 & 0.14 & 4.3 & 0.18 & 0.07 \\
Yanov & 19 & 38 & 17 & 81 & 27 & 1.4 \\
Chistogalovka & $0.35-3.1$ & 4.6 & $0.30-1.0$ & 55 & 7.3 & 0.94 \\
Cooling pond & $1.4-3.7$ & 4.4 & $0.61-2.9$ & 4.7 & 0.84 & 0.08 \\
Red Forest & $55-764$ & 41 & $180-2260$ & 297 & 1100 & 5.0 \\
Site 1 & $4.5-25$ & $16-19$ & $5.3-6300$ & $133-196$ & $0.29-210$ & 3.3 \\
Site 2 & $3.0-48$ & 74 & $11-260$ & 446 & $6.7-30$ & 7.6 \\
Site 3 & $5.5-1200$ & $1830-2760$ & $0.62-21000$ & $7440-10950$ & $1.2-180$ & 190 \\
Site 4 & $0.13-4.5$ & $1.0-1.5$ & $0.01-61$ & 8.7 & $0.08-0.15$ & 0.15 \\
Site 5 & 142 & 134 & 66 & 771 & 12 & 13 \\
\hline
\end{tabular}

Table 3. A comparison of observed (1994-96) and predicted whole-body ${ }^{90} \mathrm{Sr}$ and radiocaesium activity concentrations in rodent species sampled at various locations in the Chernobyl exclusion zone [11].

\begin{tabular}{lrrrr}
\hline & \multicolumn{2}{c}{${ }^{90} \mathrm{Sr}\left(\mathrm{kBq} \mathrm{kg}^{-1} \mathrm{fw}\right)$} & \multicolumn{2}{c}{ Radiocaesium $\left(\mathrm{kBq} \mathrm{kg}^{-1}\right)$} \\
Site name & Observed & \multicolumn{1}{c}{ Predicted } & \multicolumn{1}{c}{ Observed } & Predicted \\
\hline Chistogalovka & $1.2-70$ & $61-92$ & $0.25-34$ & 436 \\
Glyboke lake & $7.6-235$ & $71-107$ & $7.8-6490$ & 621 \\
Orchard & & & $0.25-42$ & 129 \\
Red forest enclosure & & & $3.3-42$ & 109 \\
Red Forest grassland (remediated area) & $2.2-142$ & $14-22$ & $0.50-2230$ & $109-111$ \\
Red Forest woodland & $3.8-84$ & 194 & $22-20520$ & 986 \\
\hline
\end{tabular}


The database described by Gaschak et al. [10] reports ${ }^{90} \mathrm{Sr}$ and ${ }^{137} \mathrm{Cs}$ activity concentrations in a range of predominantly large herbivorous (Alces alces, Capreolus capreolus, Cervus elaphus and Lepus spp.) and carnivorous (Vulpes vuples and Canis lupus) mammals sampled across the Chernobyl exclusion zone. The herbivorous mammal data were dominated by results for C. capreolus (63 of 68 measurements). Predictions of whole-body ${ }^{90} \mathrm{Sr}$ and ${ }^{137} \mathrm{Cs}$ activity concentrations (using GIS estimated radionuclide activity concentrations in soil) by reference organism group are compared to the database of Gaschak et al. [10] in Table 4. Whilst predicted means and ranges were close to observed values with mean predicted to observed ratios (for all species) of $9.2(0.01-110)$ and $0.8(0.09-64)$ for ${ }^{137} \mathrm{Cs}$ and ${ }^{90} \mathrm{Sr}$ respectively, there was relatively poor agreement for individual data $\left(\mathrm{R}^{2}<0.16\right)$. There was also a tendency to over-predict low observed values and under-predict high observations.

Predicted ${ }^{137} \mathrm{Cs}$ activity concentrations for detritivorous invertebrates are compared with the reported values [13] for Carabidae and 'ground dwellers' in Table 2. Strontium-90 activity concentrations were only available for Site 1 (0.53-72 kBq kg-1 fw) and Site $3\left(21-4600 \mathrm{kBq} \mathrm{kg}^{-1} \mathrm{fw}\right)$. Predicted activity concentrations were within the range of observed values at each site at $19 \mathrm{kBq} \mathrm{kg}^{-1} \mathrm{fw}$ and $2800 \mathrm{kBq} \mathrm{kg}^{-1} \mathrm{fw}$ respectively.

Table 4. A comparison of observed (1988-2000) and predicted whole-body ${ }^{90} \mathrm{Sr}$ and ${ }^{137} \mathrm{Cs}$ activity concentrations in mammalian reference organisms sampled throughout the Chernobyl exclusion zone [10].

\begin{tabular}{lcccc}
\hline Reference organism/Species & \multicolumn{2}{c}{$\mathrm{C}$ Sr $\left(\mathrm{Bq} \mathrm{kg}^{-1} \mathrm{fw}\right)$} & \multicolumn{2}{c}{${ }^{137} \mathrm{Cs}\left(\mathrm{Bq} \mathrm{kg}^{-1} \mathrm{fw}\right)$} \\
& Observed & Predicted & Observed & Predicted \\
\hline Herbivorous mammal & 5900 & 5250 & 21200 & 14210 \\
& $(70-43700)$ & $(160-105900)$ & $(30-266000)$ & $(600-299000)$ \\
Carnivorous mammal & 590 & 450 & 8700 & 20200 \\
& $(130-1100)$ & $(200-970)$ & $(690-44000)$ & $(3300-66900)$ \\
\hline
\end{tabular}

\section{DISCUSSION}

Predictions have been compared to measured values for radiocaesium and ${ }^{90} \mathrm{Sr}$ in a range of FASSET animal reference organisms encompassing a wide range of species (e.g. in the case of mammals Sorex spp. to Alces alces). In all cases, predicted values were generally within the range of observed values which is encouraging, especially given the requirement to estimate soil activity concentrations at some sampling sites. Furthermore, mean predictions were either close to observed means, or were conservative estimates being approximately an order of magnitude greater, lending confidence to the overall FASSET approach. However, some comparisons showed a tendency to under predict higher observed data. Furthermore, a number of individual animal, or site-species mean, predictions were more than one order of magnitude lower than measured values; Brown et al. [6] suggest that maximum CR values (and hence expected predicted activity concentrations) are generally within an order of magnitude of the mean CR values recommended within the FASSET framework. Some of the variation in agreement between predicted and observed data at different sites may be explicable as a consequence of variables, such as soil type [17] or in the Chernobyl zone the density of particulate deposit [15]. Some of the large mammal data [10] were used, together with that from other sources, in the derivation of the FASSET CR values [6]. It does not therefore represent a truly independent test of the FASSET CR values; especially for carnivorous mammals as Gaschak et al. [10] provided most of the radiocaesium and ${ }^{90} \mathrm{Sr} \mathrm{CR}$ values.

Predictions were made here using FASSET CR values for semi-natural pasture/heathland ecosystems which were based on environmental measurements. Recommendations are also made for mammalian reference organism in forest ecosystems [6]. These are presented as ranges in aggregated transfer parameters and are predominantly based upon model predictions. If these had been used in the assessment, predicted whole-body ${ }^{90} \mathrm{Sr}$ and radiocaesium activity concentrations would be up to circa 2 orders of magnitude higher than those in Tables 2-4. Whilst this would result in no large individual underestimations, mean predictions would be considerably higher than observed values. 
Given the time span of observed data against which comparisons have been made (1988-2003), it is perhaps worth noting that Gaschak et al. [10] did not find a long-term temporal decline in either ${ }^{90} \mathrm{Sr}$ or ${ }^{137} \mathrm{Cs}$ activity concentrations of wild mammals in the Chernobyl exclusion zone.

Predicted ${ }^{90} \mathrm{Sr}$ activity concentrations in detritivorous invertebrates, made using the CR value for herbivorous mammals (given the lack of specific values for this reference organism) were within the range of the limited data available. However, predictions were perhaps not as conservative as expected on the basis of observations of the comparative transfer of Cs and Sr to invertebrates [16].

Reported data were not available to test the predictions of all of the recommended FASSET radiocaesium and ${ }^{90} \mathrm{Sr} \mathrm{CR}$ values for terrestrial animal reference organisms (i.e. bird eggs and soil invertebrates). Moreover, a large number of radionuclides were released by the Chernobyl accident and these have been measured in soils within the exclusion zone [14,15]. It is therefore somewhat surprising that no observations of radionuclides other than radiocaesium and ${ }^{90} \mathrm{Sr}$ were available in animals. This area offers an opportunity to assess the transfer of many radionuclides, including actinide elements. From the maximum measured soil ${ }^{241} \mathrm{Am}$ activity concentrations of Gilhen et al. [13] an ${ }^{241} \mathrm{Am}$ whole-body activity concentration in herbivorous mammals at Site 5 (Figure 1; Table 2) of $4 \mathrm{~Bq} \mathrm{~kg}^{-1}$ (fw) is estimated. For the sampling sites of Gaschak et al. [10] ${ }^{241} \mathrm{Am}$ and ${ }^{239} \mathrm{Pu}$ whole-body activity concentrations in herbivorous mammals of up to 0.5 and $2 \mathrm{~Bq} \mathrm{~kg}^{-1}$ (fw) respectively can be estimated (using GIS predicted soil activity concentrations averaged over typical home ranges).

\section{Acknowledgements}

This work was supported by the EC-EURATOM $6^{\text {th }}$ Framework Programme (2002-2006) and forms part of the ERICA project (FI6R-CT-2003-508847). It utilises outputs from the EC $5^{\text {th }}$ Framework Programme FASSET (FIGE-CT-2000-00102) and EPIC (ICA2-CT-2000-10032) projects. The financial support of the EC is gratefully acknowledged and $\mathrm{CEH}$ are grateful for the co-funding from the England and Wales Environment Agency. Participation of the Ukrainian participants was facilitated through a UK Royal Society grant.

\section{References}

[1] United States Department of Energy (USDoE), A graded approach for evaluating radiation doses to aquatic and terrestrial biota. DOE-STD-1153-2002, (USDoE, Washington, 2002).

[2] D. Copplestone, S. Bielby, S.R. Jones, D. Patton, P. Daniel I. Gize, Impact Assessment of Ionising Radiation on Wildlife, R \& D Publication 128, (EA, Bristol, 2001).

[3] J. Brown, H. Thørring, A. Hosseini, (editors), The 'EPIC' impact assessment framework, deliverable for the EC Project ICA2-CT-2000-10032 (EPIC), (NRPA, Østerås, 2003).

[4] C-M. Larsson, C. Jones, J.M. Gomez-Ros, I.Zinger, (editors), Framework for assessment of environmental impact of ionising radiation in major European ecosystems, deliverable for the EC Project FIGE-CT-2000-00102 (FASSET), (SSI, Stockholm, 2004).

[5] D. Copplestone, M.D. Wood, S. Bielby, S.R. Jones, J. Vives, N. A. Beresford, Habitat regulations for Stage 3 assessments: radioactive substances authorisations, R \& D Technical Report P3-101/SP1a, (EA, Bristol, 2003).

[6] J. Brown, P. Strand A. Hosseini, P. Børretzen (editors), Handbook for assessment of the exposure of biota to ionising radiation from radionuclides in the environment, deliverable for the EC Project FIGE-CT-2000-00102 (FASSET), (NRPA, Østerås, 2003).

[7] N.A. Beresford, S.M. Wright, C.L. Barnett, J.L. Hingston, J. Vives i Batlle, D. Copplestone, I.I. Kryshev, T.G. Sazykina, G. Pröhl, A. Arkhipov, B.J. Howard, Radioprotection (colloques), this issue, submitted.

[8] N.A. Beresford, M.R. Broadley, B.J. Howard, C.L. Barnett, P.J. White, J. Rad. Prot., in press. 
[9] T.G. Sazykina, A. Jaworska, J. Brown, (editors), Dose effects relationships for reference (or related) Arctic biota, deliverable for the EC Project ICA2-CT-2000-10032 (EPIC), (NRPA, Østerås, 2003).

[10] S. Gaschak, I. Chizhevsky, A. Arkhipov, N.A. Beresford, C.L. Barnett, in Conference on the Protection of the Environment from the Effects of Ionizing Radiation, IAEA-CN-109, (IAEA, Stockholm, 2003). p. 200.

[11] R.K. Chesser, D.W. Sugg, M.D. Lomakin, R.A. Van Den Bussche, A.J. DeWoody, C.H. Jagoe, C.E. Dallas, F.W. Whicker, M.H. Smith, S.P. Gaschak, I.V. Chizhevsky, V.V. Lyabik, E.G. Buntova, K. Holloman, R.J. Baker, Env. Toxicol. Chem., 19, 305 (2000).

[12] R.J. Baker, M.J. Hamilton, R.A. Van Den Bussche, L.E. Wiggins, D.W. Sugg, M.H. Smith, M.D. Lomakin, S.P. Gaschak, E.G. Buntova, G.A. Rudenskaya, R.K Chesser, J. Mammal, 77, 155 (1996).

[13] M. Gilhen, K. Cooper, K. Radbourne, \& R. Carrington, MSc. theses, University of Liverpool. 2001 - 2003.

[14] K Mück. G. Prohl, I. Likhtarev, L. Kovgan, R. Meckbach, V. Golikov, Hlth. Phys., 82, 141 (2002).

[15] UIAR, Contamination of the ChNPP 30-km zone, (UIAR, Chabany, 2001), CD v2.

[16] D.A. Crossley, in Radioecology, V. Schultz, A.W. Klement, (editors), (Reinhold, New York, 1963) p103.

[17] A.G. Gillett, N.M.J. Crout, S.M. Absalom, S.M. Wright, S.D. Young, B.J. Howard, C.L. Barnett, S.P. McGrath, N.A. Beresford, G. Voigt, Rad. Environ. Biophys., 40, 227 (2001). 